after immunotherapy (end of study), $65 \%$ mice receiving $\mathrm{Ad}+\mathrm{V} 10-30 \mathrm{mg}$ $\mathrm{m} 2 /$ day survived. CCNU $9 \mathrm{mg} / \mathrm{m} 2$ failed to improve $\mathrm{mOS}$ while $18 \mathrm{mg} / \mathrm{m} 2$ increased $\mathrm{mOS}$ to 36 days. Ad+V $3 \mathrm{mg} / \mathrm{m} 2$ combined with CCNU $9 \mathrm{mg} / \mathrm{m} 2$ failed to improve mOS while $\mathrm{Ad}+\mathrm{V} 3 \mathrm{mg} / \mathrm{m} 2+\mathrm{CCNU} 18 \mathrm{mg} / \mathrm{m} 2$ increased survival with $60 \%$ surviving at study end. Ad+V $10 \mathrm{mg} / \mathrm{m} 2+\mathrm{CCNU} 9 \mathrm{mg} / \mathrm{m} 2$ failed to increase mOS over monotherapy while $\mathrm{Ad}+\mathrm{V} 10 \mathrm{mg} / \mathrm{m} 2+\mathrm{CCNU}$ $18 \mathrm{mg} / \mathrm{m} 2$ resulted in $100 \%$ survival at end of study. Ad+V $30 \mathrm{mg} / \mathrm{m} 2+\mathrm{CCNU}$ $(9-18 \mathrm{mg} / \mathrm{m} 2)$ did not further improve survival with increased clinical signs over monotherapy that recovered on discontinuance of dosing. $\mathrm{Ad}+\mathrm{V}$ increased tumor IL-12 (80 pg/mg) which was $\sim 15$-times greater than that of plasma while CCNU alone or in combination with $\mathrm{Ad}+\mathrm{V}$ did not affect tumor and serum cytokines. Within the tumor, $\mathrm{Ad}+\mathrm{V}$ elicited a dose-related increase in cytotoxic $\mathrm{T}$ cells and macrophages and decrease in regulatory $\mathrm{T}$ cells consistent with immune-mediated anti-tumor effects. Ad+V+CCNU did not further alter the tumor immune profile over Ad+V monotherapy. In summary, the controlled local immunostimulation with IL-12 combined with CCNU, warrants further investigation in GBM.

\section{IMMU-34. CONTROLLED EXPRESSION OF IL-12 IMPROVES SURVIVAL IN GLIOMA BY ACTIVATING THE IMMUNE RESPONSE IN MICE AND HUMANS}

John Barrett ${ }^{1}$, Hongliang Cai ${ }^{1}$, John Miao ${ }^{1}$, Pranay Khare ${ }^{1}$, Tim Chan ${ }^{2}$, Laurence Cooper ${ }^{1}$ and Francois Lebel ${ }^{1}$; ${ }^{1}$ Ziopharm Oncology, Boston, MA, USA, ${ }^{2}$ Intrexon Corporation, Germantown, MD, USA

Modulating the tumor microenvironment with immuno-stimulatory therapy maybe an attractive approach for the treatment of glioma. We took advantage of IL-12 biology utilizing a replication-incompetent adenovirus (Ad) engineered to conditionally express mouse or human IL-12 (Ad-RTSmIL-12 or Ad-RTS-hIL-12), via our RheoSwitch Therapeutic System ${ }^{\circledR}$ (RTS $\left.{ }^{\circledR}\right)$ gene switch, tightly controlled by the oral activator ligand veledimex (V). Previous human and mouse studies demonstrated that $\mathrm{V}$ crosses the bloodbrain-barrier (BBB), enabling controlled IL-12 expression. Ad-RTS-mIL-12 injected into orthotopic GL-261 glioma at the optimal dose of $5 \times 10^{9}$ viral particles $(\mathrm{vp})+$ veledimex $(\mathrm{Ad}+\mathrm{V})$ elicited dose-related increases in local IL-12 and downstream IFN-gamma production. Cytokines within the tumor were $\sim 20$ times higher than serum and elicited sustained increases within glioma of cytotoxic $\mathrm{T}$ cells and macrophages concomitant with reduction in regulatory $\mathrm{T}$ cells $\left(\mathrm{T}_{\text {regs }}\right)$ resulting in enhanced survival where $\sim 65 \%$ of mice receiving $\mathrm{Ad}+\mathrm{V} 10-30 \mathrm{mg} / \mathrm{m}^{2} /$ day were tumor free 80 days after immunotherapy (end of study). Ad+V $10 \mathrm{mg} / \mathrm{m}^{2} /$ day was the optimal therapeutic index. Using allometric modeling, mouse $\mathrm{Ad}+\mathrm{V} 10 \mathrm{mg} / \mathrm{m}^{2} /$ day translated into $\sim 20 \mathrm{mg} \mathrm{V}$ for a $70 \mathrm{~kg}$ subject and supports Ad-RTS-hIL-12 up to $5 \times 10^{12} \mathrm{vp}$. Based on these results, a phase 1 trial in recurrent glioma studying local hIL-12 production using AdRTS-hIL-12 2x10 $11 \mathrm{vp}+\mathrm{V}$ 10-40mg QDx14po. was initiated. Interim results demonstrated that V20mg elicited the optimal therapeutic index. Results at $20 \mathrm{mg}(\mathrm{N}=15)$ demonstrated that $\mathrm{V}$ crossed the BBB with $35 \pm 5 \%$ of plasma levels in tumor and peak serum levels of hIL-12 and IFN-gamma at 27 and $36 \mathrm{pg} / \mathrm{ml}$. Increase in circulating cytotoxic- $\mathrm{T}$ cell $/ \mathrm{T}_{\mathrm{regs}}$ ratio at days $14-28 \mathrm{cor}-$ related with an increase in the median overall survival of $12.5 \mathrm{mo}$. Our working hypothesis tested in the mouse that IL-12 activates the immune response leading to mouse anti-tumor effects now appears to be validated in humans.

\section{IMMU-35. TARGETING IDO1 IN HUMAN PEDIATRIC BRAIN} CANCER

Kristen Lauing ${ }^{1}$, Rishi Lulla ${ }^{2}$, Alicia Lenzen ${ }^{1}$, Lijie Zhai ${ }^{1}$

Rintaro Hashizume $^{1}$, Jason R Fangusaro ${ }^{2}$ and Derek Wainwright ${ }^{1}$; ${ }^{1}$ Department of Neurological Surgery, Northwestern University Feinberg School of Medicine, Chicago, IL, USA, ${ }^{2}$ Department of Pediatric-

Hematology, Oncology and Stem Cell Transplantation, Northwestern University Feinberg School of Medicine, Chicago, IL, USA

Indoleamine 2,3 dioxygenase 1 (IDO1) is a rate-limiting enzyme that converts tryptophan (Trp) into kynurenine (Kyn) and has been confirmed to suppress the immune response in adults diagnosed with malignant glioma. To address the role of IDO1 in pediatric high grade glioma (HGG) we investigated its expression in surgically-resected human pediatric HGG and in primary HGG cell lines that included diffuse intrinsic pontine glioma (DIPG). Utilizing qRT-PCR, two populations of gliomas were found based on high ( $>3$ fold expression compared to control) versus low ( $<3$ fold) IDO1 expression in patient tumor tissue. Notably, DIPG universally expressed low IDO1 levels when compared to HGG. In vitro, HGG cells inducibly expressed IDO1 protein and mRNA by 8 hours post-IFN $\gamma$ treatment. At $\geq 250 \mathrm{nM}, \mathrm{BGB}-5777$ [a novel, pharmaceutical-grade IDO1 enzyme inhibitor (Beigene)] significantly decreased the Kyn/Trp ratio in HGG and DIPG cell lines stimulated with IFN $\gamma(P<0.001)$, while $250 \mathrm{nM}-1 \mu \mathrm{M} L 1-\mathrm{MT}$ and D1-MT had no impact on Trp and Kyn levels. Unexpectedly, BGB-5777 induced a significant increase in IDO1 protein levels at 24 and 48 hours post-treatment. These data demonstrate that, IDO1 is expressed in pediatric HGG and can be targeted with an enzyme inhibitor, but that it unexpect- edly leads to IDO1 protein stability. Given that IDO1 enzyme inhibitors are under evaluation in adults with brain cancer, these data suggest that BGB-5777 may be a valuable agent for future therapeutic consideration in children with malignant glioma.

\section{IMMU-36. HYPERGLYCEMIA SUPPRESSES MACROPHAGE} ACTIVITY AND INHIBITS GLIOMA INVASION IN DIABETIC MICE Ian Zhang ${ }^{1}$, Huili Liu ${ }^{1}$, Hui Zhou ${ }^{1}$, Leying Zhang ${ }^{1}$, Behnam Badie ${ }^{2}$ and Darya Alizadeh ${ }^{3} ;{ }^{1}$ City of Hope Beckman Research Institute, Duarte, CA, USA, ${ }^{2}$ Division of Neurosurgery, City of Hope, Duarte, CA, USA, ${ }^{3}$ City of Hope Comprehensive Cancer Center, Duarte, CA, USA

Patients with malignant glioma (MG) are often treated with corticosteroids to reduce cerebral edema, but chronic use of steroids may cause glucose intolerance and development of type 2 diabetes $(\mathrm{Db})$. Individuals with $\mathrm{Db}$ not only have significantly higher likelihood of developing malignant tumors, but also, have a higher risk of cancer-related mortality than non-Db patients. The goal of this study was to evaluate the effect of hyperglycemia on glioma growth in mouse models. Because MG are heterogeneous tumors with both invasive and "nodular" phenotypes, two different syngeneic glioma models were examined in streptozotocin-induced $\mathrm{Db}$ mice. We found that in the GL261 gliomas that typically grow as "nodular" tumors, hyperglycemia activated receptor for advanced glycation endproducts (RAGE) by upregulating HMGB1 expression, and promoted tumor growth irrespective of tumor microenvironment (TME). Similarly, the K-Luc gliomas, which are invasive and elicit a robust macrophage infiltration, grew faster in subcutaneous (s.c.) location in $\mathrm{Db}$ mice. However, intracranial (i.c.) K-luc gliomas were smaller and less invasive in hyperglycemic mice. Our studies showed that a reduction in K-Luc growth in the brains of $\mathrm{Db}$ mice was mostly due to the abrogation of inflammatory responses and suppression of pro-inflammatory cytokines such as IL-1b and IL-6 in TME. We conclude that hyperglycemia may enhance glioma growth by activating the RAGE pathway and suppressing antitumor responses. But, suppression of tumor inflammation may also inhibit glioma growth by abrogating i.c. tumor invasion under hyperglycemic conditions.

IMMU-37. METABOLIC REPROGRAMMING OF THE GLIOMA MICROENVIRONMENT INHIBITS TUMOR IMMUNOSUPPRESSION Jason Miska, Megan Muroski, Aida Rashidi, Alan Chang, Peng Zhang, Yu Han and Maciej S Lesniak; Department of Neurological Surgery, Feinberg School of Medicine, Northwestern University, Chicago, IL, USA

INTRODUCTION: Anti-tumor immunity in murine models of glioblastoma is potently suppressed by regulatory T-cell (Treg) accumulation within the tumor. Recent studies have highlighted that both glioma and immunosuppressive cellular subsets utilize fatty acid metabolism for survival. Inhibition of fatty acid oxidation (FAO) prolongs survival in glioma bearing mice, however, the immunity of tumor microenvironment (TME) upon inhibition of this pathway is not known. METHODS: In this study we looked at the immunological effects of etomoxir, an inhibitor of mitochondrial import of fatty acids (FA) on an intracranial model of glioma. We tested both intracranial and systemic administration of this inhibitor to understand effects on systemic immunity as well as specifically within the TME. RESULTS: Glioma bearing mice had significantly increased free fatty acids within the interstitial fluid of the tumor, suggesting this may be an abundant energy source within this environment. We measured the effect of etomoxir on the GL261 murine tumor line, and found minimal effects on glioma cultures, with cytostatic effects occurring only at very high concentrations. Through the use of a novel nanoparticle-FA sensor, we observed that Tregs uptake significantly more FA compared to effector T-cells in tumor bearing mice and may be the target of FAO inhibition. We demonstrate a significant increase in survival with intracranial etomoxir treatment $(\mathrm{p}<0.01, * *)$, which does not occur in immunodeficient animals. Both intracranial and systemic Etomoxir treatment caused a significant decrease in total number of Tregs within the glioma tissue, with a concomitant increase in CD8 T-cell functionality. CONCLUSIONS: Our data suggests that that FA metabolism contributes to the immunosuppressive TME, and may be a metabolic target to enhance immunotherapy against glioma.

IMMU-38. GLIOBLASTOMA-DERIVED IL-6 INDUCES IMMUNOSUPPRESSIVE PERIPHERAL MYELOID CELL PD-L1 EXPRESSION AND TUMOR PROGRESSION

Jonathan Lamano ${ }^{1}$, Jason Lamano ${ }^{1}$, Winward Choy ${ }^{2}$, Dorina Veliceasa ${ }^{1}$, Joseph DiDomenico ${ }^{1}$, Daniel Oyon ${ }^{1}$, Jessica Quaggin-Smith ${ }^{1}$ Shayan Fakurnejad ${ }^{3}$, Leonel Ampie ${ }^{4}$, Derek $\mathrm{Li}^{1}$, Kartik Kesavabhotla ${ }^{1}$, Rajwant Kaur ${ }^{1}$, C. David James ${ }^{1}$, Andrew Parsa ${ }^{1}$ and Orin Bloch ${ }^{1}$; ${ }^{1}$ Department of Neurological Surgery, Northwestern University Feinberg School of Medicine, Chicago, IL, USA, ${ }^{2}$ Department of Neurological Surgery, University of California, San Francisco, San Francisco, CA, USA, 